\title{
Wykrywanie uszkodzeń w konstrukcji samolotu w trakcie realizacji pełnoskalowej próby zmęczeniowej z wykorzystaniem czujników zintegrowanych
}

\section{Damage detection in the aircraft structure during the full scale fatigue test with the use of integrated sensors operated}

\section{Streszczenie}

Opracowanie niezawodnych systemów zautomatyzowanego monitorowania stanu konstrukcji lotniczych (SHM), pozwalających na zdalną ocenę stanu danego statku powietrznego oraz obniżenie kosztów jego eksploatacji stanowi jeden z wiodących kierunków rozwoju technologii w przemyśle lotniczym. Jedną z idei budowy takiego systemu jest wykorzystanie fal Lamba wzbudzonych w danym elemencie konstrukcji przez sieć przetworników piezoelektrycznych PZT. W artykule przedstawiono holistyczną koncepcję detekcji uszkodzeń oraz bieżącego monitorowania ich rozwoju w strukturze samolotu. Trzon systemu stanowią czujniki PZT, uzupełnione w wybranych lokalizacjach przez czujniki rezystancyjne oraz próżniowe $\mathrm{CVM}^{\mathrm{TM}}$. W artykule poruszono wybrane zagadnienia związane z opracowywanym systemem, w szczególności dotyczące wnioskowania o obecności oraz rozwoju uszkodzenia, jak również przedstawiono przykładowy wynik działania systemu.

\section{Abstract}

Providing reliable and universal Structural Health Monitoring (SHM) system allowing for remote aircraft inspections and maintenance costs reduction is one of the major issues in the aerospace industry. SHM based on guided Lamb waves is one of the approach able to address the matter and satisfy all the requirements. In the paper a holistic approach for the continous real time damage growth monitoring and early damage detection of the aircraft structure is presented. The main component of the system is piezoelectric transducers (PZT) network. These are complemented by other SHM methods: Comparative Vacuum Monitoring $\left(\mathrm{CVM}^{\mathrm{TM}}\right)$ and Resistance Gauges at selected aircraft hot-spots. Description of damage detection capabilities are delivered in the paper. In particular some issues concerning the statistical inference about a damage presence and its growth are discussed.

\section{Wstęp}

Monitorowanie konstrukcji lotniczych z uwagi na możliwość wystąpienia uszkodzeń jest istotnym czynnikiem systemu eksploatacji statków powietrznych

Dr inż. Krzysztof Dragan, mgr Michał Dziendzikowski, mgr inż. Artur Kurnyta, inż. Adam Latoszek - Instytut Techniczny Wojsk Lotniczych.

(SP) [1]. Obecnie stosowane techniki diagnostyczne obejmują w większości przeglądy wizualne lub przeglądy z wykorzystaniem metod badań nieniszczących NDT (Non Destructive Testing - NDT) [2, 3]. Stosowane metody przeglądów są czasochłonne i kosztowne, a wyniki badań zależne od tzw. czynnika ludzkiego (doświadczenia personelu wykonującego badania oraz czynników takich jak zmęczenie osoby wykonującej badanie, temperatury otoczenia, oświetlenia, 
hałasu itp.) [4]. Czasochłonność i koszty są związane z odpowiednią ilością czasu pracy personelu technicznego, jak również często koniecznością demontażu niektórych elementów SP. Stosowanie nowoczesnych technik diagnostycznych opartych na zautomatyzowanych badaniach nieniszczących znacząco zmniejsza ilość składowych wpływających na zależność wyników badań od czynników zewnętrznych, jak również zmniejsza czas badania [5]. Kolejną istotną zaletą jest możliwość rejestracji i archiwizacji wyników w celu późniejszego porównywania, co stanowi wstęp do ciągłego monitorowania. Jednakże takie badania muszą być wykonywane w określonych odstępach, co powoduje wyłączanie SP z eksploatacji na czas przeglądu. Alternatywą jest zastosowanie monitorowania takich struktur $z$ wykorzystaniem odpowiednich metod umożliwiających rejestrację sygnału bez konieczności demontażu elementu lub wyłączania go na dłuższy czas z eksploatacji. Metody takie polegają na zabudowaniu w określonych, krytycznych elementach - odpowiednich czujników pomiarowych, dokonujących pomiaru za pomocą metod odpowiednich dla klasyfikacji, i wykrycia poszczególnych rodzajów uszkodzeń i należą do grupy technik określanych jako monitorowanie struktury (tzw. Structural Health Monitoring - SHM) [6, 7]. W artykule przedstawione zostanie podejście do monitorowania konstrukcji lotniczych z wykorzystaniem czujników piezoelektrycznych (PZT) generujących fale sprężyste, opracowywanym w ramach projektu SYMOST $[8,9]$.

\section{Systemy monitorowania struktury samolotu}

Jako platformę do testowania opracowywanych rozwiązań wykorzystano samolot PZL-130 TCII Orlik, używany $w$ celach szkoleniowych przez Siły Zbrojne RP. Ze względu na zmiany konstrukcyjne w najnowszej wprowadzanej do służby wersji samolotu oraz opracowywany system eksploatacji według stanu technicznego, samolot przechodzi pełnoskalową próbę zmęczeniową, co daje możliwość weryfikacji różnorodnych systemów monitorowania stanu struktury na rzeczywistej konstrukcji w długim horyzoncie czasowym. Trzy różne rodzaje czujników zainstalowano w wytypowanych punktach konstrukcji, najbardziej narażonych na wystąpienie pęknięć zmęczeniowych: czujniki próżniowe $\mathrm{CVM}^{\mathrm{TM}}$ (rys. 1), czujniki rezystancyjne (rys. 2) oraz czujniki piezoelektryczne PZT (rys. 1 i 2). W wielu punktach konstrukcji systemy są zdublowane, co umożliwia bezpośrednie porównanie ich działania. Odczyt danych oraz sterowanie systemami monitorowania odbywa się zdalnie za pośrednictwem Internetu, co umożliwia natychmiastową weryfikację ich wskazań standardowymi metodami badań nieniszczących. W ramach projektu SYMOST dotyczącego rozwoju technologii monitorowania struktur lotniczych w oparciu o czujniki piezoelektryczne, rozpatrywane są m.in. następujące zagadnienia:

- analiza sygnałowa, w tym opracowanie optymalnych metod transformacji sygnału pod kątem wykrywania pęknięć zmęczeniowych i szacowania ich rozmiaru;

- opracowanie i weryfikacja metod wnioskowania statystycznego;

- opracowanie i weryfikacja narzędzi autodiagnostyki czujników sieci pomiarowej;

- opracowanie architektury zdalnej jednostki monitorującej z wykorzystaniem procesora sygnałowego DSP.

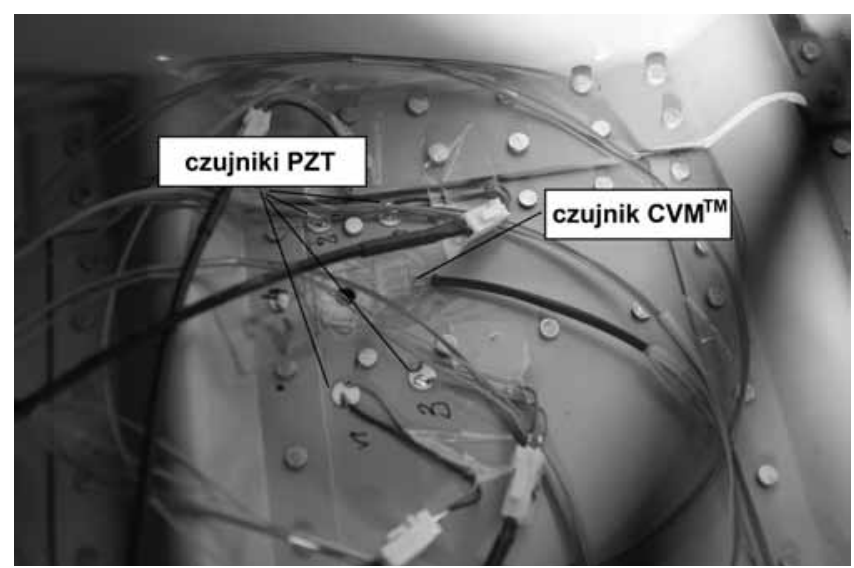

Rys. 1. Monitorowany punkt konstrukcji samolotu z zainstalowanymi czujnikami piezoelektrycznymi oraz czujnikiem próżniowym

Fig. 1. Monitored location in the aircraft structure with installed PZT and vacuum sensors

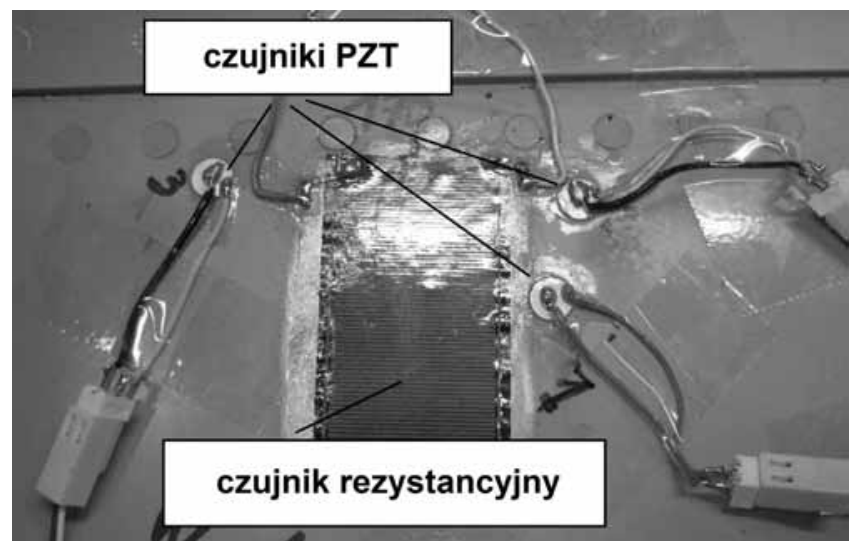

Rys. 2. Monitorowany punkt konstrukcji samolotu z zainstalowanymi czujnikami piezoelektrycznymi oraz czujnikiem rezystancyjnym

Fig. 2. Monitored location in the aircraft structure with installed PZT and resistive ladder

\section{Monitorowanie konstrukcji z zastosowaniem czujników piezoelektrycznych}

Jedną $z$ idei budowy systemów bieżącego monitorowania konstrukcji jest wykorzystanie mechanicznych właściwości materiałów użytych przy produkcji danego elementu statku powietrznego. Opiera się ona na rejestracji przebiegu fal mechanicznych wzbudzonych 
w danym ośrodku przez sieć przetworników piezoelektrycznych (PZT) [10]. Rozwiązanie dynamiki małych odkształceń ośrodka silnie zależy od warunków brzegowych danego zagadnienia, szczególnie od geometrii danego układu, w tym także jej lokalnych zmian spowodowanych nieciągłościami i deformacją struktury. Uszkodzenia wywołanym przez wpływ na lokalna geometrię danego elementu mogą dać widoczny efekt w przebiegu czasowym rejestrowanych sygnałów. Efekt ten może jednak istotnie zależeć od ich umiejscowienia w sieci pomiarowej. Na rejestrowany sygnał wpływa zatem obecność uszkodzenia, jego rodzaj i rozmiary oraz lokalizacja względem sensorów sieci pomiarowej.

Propagacja fal sprężystych w elementach cienkościennych o małej krzywiźnie jest zjawiskiem stosunkowo złożonym. Dla danej częstotliwości sygnału wymuszającego mogą współistnieć różne mody falowe o różnych prędkościach propagacji, które zależą m.in. od grubości danego elementu oraz modułów sprężystości danego materiału [11].

Automatycznego wnioskowania o stanie badanego obiektu dokonuje się zwykle na podstawie uproszczonych charakterystyk rejestrowanego sygnału, tzw. wskaźników uszkodzeń (ang. damage indices). Oznaczając przez $f_{\text {gs }}$ sygnał wygenerowany przez generator $g$ i zarejestrowany przez sensor $s$ dla danego stanu struktury, $f_{g s}$ env jego obwiednię, przez $f_{g s, b}, f_{g s, b}$ env odpowiadający sygnał odniesienia wraz z obwiednią, zarejestrowany dla nieuszkodzonej struktury oraz przez $\operatorname{cor}\left(f_{g s}^{\text {env }}, f_{g s, b}^{\text {env }}\right)$ próbkową korelację obwiedni, proponowane wskaźniki uszkodzeń można zapisać następująco:

$$
\begin{aligned}
& D I_{1}(g, s)=1-\operatorname{cor}\left(f_{g s}^{\text {env }}, f_{g s, b}^{e n v}\right) \\
& D I_{2}(g, s)=\left|\frac{\int\left(f_{g s}^{\text {env }}-f_{g s, b}^{e n v}\right)^{2} d t}{\int\left(f_{g s, b}^{e n v}\right)^{2} d t}\right|
\end{aligned}
$$

Powyższe wskaźniki uszkodzeń są wrażliwe na zmiany energii rejestrowanego sygnału związane z rozproszeniem fali elastycznej na pęknięciu. Konfiguracja sieci może w czasie eksploatacji konstrukcji ulec niewielkim zmianom ze względu na złożony zestaw obciążeń, jakim są one poddawane. Dla sygnałów o stosowanych w systemie częstotliwościach różnice w konfiguracji mogą spowodować zmianę fazy rejestrowanego sygnału. Proponowane wskaźniki uszkodzeń są odporne na te zaburzenia, czemu służy $\mathrm{m}$. in. wykorzystanie obwiedni sygnałów oraz ich różnic. Wprowadzone charakterystyki sygnału zależą od lokalizacji uszkodzenia względem danej ścieżki pomiarowej $g \rightarrow s$, zatem ich bezpośrednie wykorzystanie w modelach szacowania rozmiaru uszkodzeń jest utrudnione. W celu zmniejszenia zależności wskazań systemu od lokalizacji uszkodzenia proponowane jest wykorzystanie tzw. uśrednionych wskaźników uszkodzeń [8]:

$$
A D I_{j}=\frac{1}{n(n-1)} \sum_{\substack{\mathrm{g}, \mathrm{s}: \\ \mathrm{g} \neq \mathrm{s}}} D I_{j}(g, s), \mathrm{j}=1,2
$$

gdzie $n$ jest liczbą sensorów w danej komórce sieci, zaś $D I_{j}(g, s)$ oznacza wybrany wskaźnik uszkodzeń (1). Uśrednione wskaźniki uszkodzeń są niezmiennicze ze względu na permutacje czujników i mogą być wykorzystane w statystycznych modelach klasyfikacyjnych i regresji.

$\mathrm{Na}$ wykresie (rys. 3) przedstawiono uśrednione wskaźniki uszkodzeń (1) i (2) dla wybranego węzła pomiarowego, gdzie wystąpiły uszkodzenia. Widoczna jest dobra separacja grup danych odpowiadających kolejnym rzędom wielkości uszkodzeń.

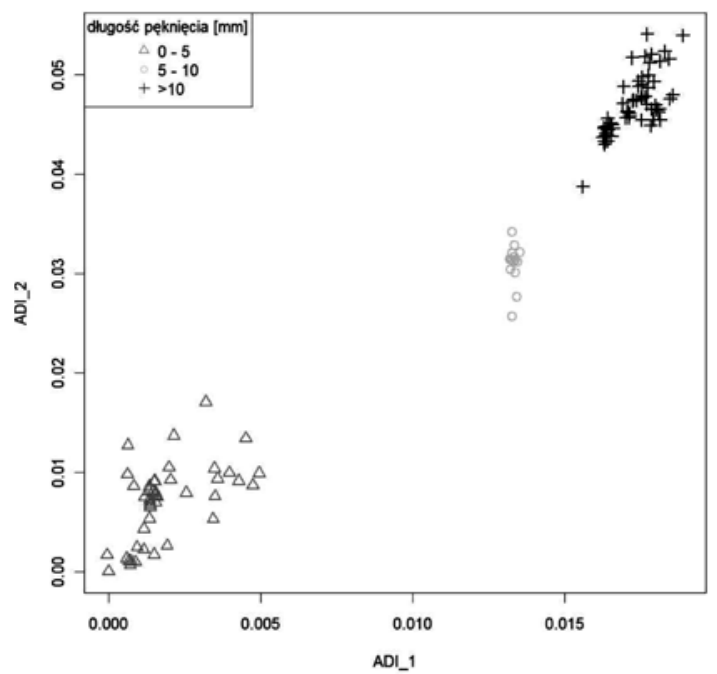

Rys. 3. Uśrednione wskaźniki uszkodzeń dla wybranego węzła pomiarowego

Fig. 3. Averaged damage indices for the selected monitoring node 


\section{Podsumowanie}

W artykule przedstawiono jedynie część problematyki dotyczącej realizowanego projektu SYMOST dotyczącego budowy systemów monitorowania stanu technicznego konstrukcji lotniczych w oparciu o czujniki piezoelektryczne PZT. Opracowano oprogramowanie do analizy sygnałów, filtracji i przetwarzania w dziedzinie czasu i częstotliwości, umożliwiające bieżące monitorowanie stanu konstrukcji on-line. Na podstawie przetworzonych danych opracowana zostanie kolejna warstwa oprogramowania pozwalająca na klasyfikowanie uszkodzeń i podejmowanie decyzji z wykorzystaniem metod statystycznych, w tym bayesowskich modeli decyzyjnych i sieci neuronowych. Całość umożliwi budowę systemu $z$ wbudowanym oprogramowaniem sterującym i decyzyjnym z użyciem procesorów sygnałowych, np. jednostek DSP. Sprawnie działające systemy monitorowania uszkodzeń pozwolą na rozwój nowych koncepcji eksploatacji statków powietrznych, wpływając pozytywnie na bezpieczeństwo lotów przy jednoczesnym obniżeniu kosztów utrzymania systemu.

\section{Literatura}

[1] Lewitowicz J.: Podstawy Eksploatacji Statków Powietrznych T-1, Wydawnictwo ITWL Warszawa 2001.

[2] Aging of U.S. Air Force Aircraft, Final Report, Publication NMAB-488-2, National Academy Press, USA, Washington D.C. 1997.

[3] NDE of Cracks in Aircraft, NTIAC - SR-98-04, USA, Texas 1998.

[4] Dragan K., Klimaszewski S.: In-Service NDI of Aging Helicopters Main Rotor Blades Used In Polish Armed Forces, 9th Joint FAA/DoD/NASA Aging Aircraft Conference, Atlanta, 06 $\div 09$ Marzec, 2006.

[5] Dragan K., Klimaszewski S.: In-service Flaw Detection and Quantification on the MiG-29 Composite Vertical Tail Skin, 9th European Conference on Non-Destructive Testing, Berlin 25-29 Września 2006.

[6] Rücker W.: SAMCO Final Report 2006, Guideline for Structural Health Monitoring", Federal Institute of Materials Research and Testing (BAM), Berlin 2006.
[7] Doebling S. W., Farrar Daniel Ch. R.: Damage Identification and Health Monitoring of Structural and Mechanical Systems from Changes in Their Vibration Characteristics: A Literature Review, Los Alamos National Laboratory, Los Alamos 1996.

[8] Dragan K., Dziendzikowski M.: T. Uhl, The development of the non-parametric classification models for the damage monitoring on the example of the ORLIK aircraft structure, Key. Eng. Mat. Vol. 518, 2012

[9] Dragan K., Dziendzikowski M, Klimaszewski S., Kłysz S., Kurnyta A.: Energy Correlated Damage Indices in Fatigue Crack Extent Quantification, Key. Eng. Mat. Vol. 570, 2013

[10] Su Z. and Ye L.: 'Identification of Damage Using Lamb Waves', Springer-Verlag, Niemcy, 2009

[11] Graff K., 'Wave motion in elastic solids', Oxford University Press, Oxford, 1975

\section{Miesięczne i roczne spisy treści oraz streszczenia artykułów opublikowanych w Przeglądzie Spawalnictwa są dostępne na stronie internetowej:}

wWw.pspaw.ps.pl 